\title{
Isolation of Mitochondria from Potato Tubers
}

Jesper F. Havelund ${ }^{1,2}$, Fernanda Salvato ${ }^{3,4}$, Mingjie Chen $^{3}$, R.S.P. Rao ${ }^{3}$, Adelina RogowskaWrzesinska ${ }^{2}$, Ole N. Jensen², David R. Gang ${ }^{5}$, Jay J. Thelen ${ }^{3}$ and lan Max Møller ${ }^{1^{*}}$

${ }^{1}$ Department of Molecular Biology and Genetics, Science and Technology, Aarhus University, Slagelse, Denmark; ${ }^{2}$ Department of Biochemistry and Interdisciplinary Plant Group, University of Missouri-Columbia, Columbia, USA; ${ }^{3}$ Department of Biochemistry and Interdisciplinary Plant Group, University of Missouri-Colum, Columbia, USA; ${ }^{4}$ Department of Biochemistry and Molecular Biology, University of Southern Denmark, Odense M, Denmark; ${ }^{5}$ Institute of Biological Chemistry, Washington State University, WA, USA

*For correspondence: ian.max.moller@agrsci.dk

[Abstract] One way to study the function of plant mitochondria is to extract them from plant tissues in an uncontaminated, intact and functional form. The reductionist assumption is that the components present in such a preparation and the in vitro measurable functions or activities reliably reflect the in vivo properties of the organelle inside the plant cell. Here, we describe a method to isolate mitochondria from a relatively homogeneous plant tissue, the dormant potato tuber. The homogenization is done using a juice extractor, which is a relatively gentle homogenization procedure where the mitochondria are only exposed to strong shearing forces once. After removal of starch and large tissue pieces by filtration, differential centrifugation is used to remove residual starch as well as larger organelles. The crude mitochondria are then first purified by using a step Percoll gradient. The mitochondrial band from the step gradient is further purified by using a continuous Percoll gradient. The gradients remove contaminating amyloplasts and peroxisomes as well as ruptured mitochondria. The result is a highly purified, intact and functional mitochondrial preparation, which can be frozen and stored in liquid nitrogen in the presence of $5 \%(\mathrm{v} / \mathrm{v})$ dimethylsulfoxide to preserve integrity and functionality for months.

\section{Materials and Reagents}

1. Mannitol

2. 3-morpholinopropane-1-sulfonic acid (MOPS)

3. Potassium hydroxide $(\mathrm{KOH})$

4. Bovine serum albumin (BSA)

5. Ethylenediaminetetraacetic acid (EDTA)

6. Cysteine

7. Percoll 
8. Sucrose

9. Dimethylsulfoxide (DMSO)

10. Liquid nitrogen

11. Extraction medium (see Recipes)

12. Wash buffer (see Recipes)

13. Gradient buffers (see Recipes)

14. Percoll gradients (see Recipes)

\section{Equipment}

1. Potato tubers

2. $6 \times 250 \mathrm{ml}$ precooled angle rotor (e.g., Beckman Coulter, model: JA-14 or Thermo Fisher Scientific, model: SLA-1500)

3. $8 \times 50 \mathrm{ml}$ pre-cooled angle rotor (e.g., Beckman Coulter, model: JA-20 or Thermo Fisher Scientific, model: SS-34)

4. Juice extractor (kitchen appliance, e.g. Maginix Le duo $\mathrm{XL}$ )

5. Centrifuge (for 50 and $250 \mathrm{ml}$ tubes) (e.g. Beckman Coulter or Sorvall ${ }^{\mathrm{TM}}$ )

6. Paint brush (soft)

7. Cotton cloth or nylon net (e.g., mesh 60-120 $\mu \mathrm{m})$

8. Plastic Pasteur pipettes

9. Beakers

10. Measuring pipette

11. $\mathrm{pH}$ meter

12. Potato peeler

13. Funnel

\section{Procedure}

Notes:

a. All steps should be performed at $0-4{ }^{\circ} \mathrm{C}$ using detergent-free glass-ware or plastic!

b. We will here describe the isolation of mitochondria from $1 \mathrm{~kg}$ of peeled tubers of the cultivar Folva. This will give a final yield of 8-12 mg mitochondrial proteins. Using other cultivars can give different yields. Total time from start of the homogenization (point 3) to freezing about $6 h$.

1. Pre-cool centrifuge rotor.

2. Add cysteine and BSA to extraction buffer, adjust to $\mathrm{pH}$ 7.3. Cysteine is an antioxidant and BSA binds fatty acids and phenolics, which can interfere with mitochondrial function, 
BSA also works as a protease substrate to help protect the mitochondrial proteins from damage.

3. Peel potatoes and homogenize the peeled potato using a juice extractor ( $1 \mathrm{~kg}$ gives approximately $500 \mathrm{ml}$ juice) and let the juice run directly into about $1 / 2$ volume extraction medium (250 ml here). Adjust to $\mathrm{pH} 7.2$ using $2 \mathrm{M} \mathrm{KOH}$ immediately afterwards or, for larger preparations, after each $\mathrm{kg}$ homogenized.

4. Leave homogenate (total volume about $750 \mathrm{ml}$ ) standing for $5 \mathrm{~min}$ allowing starch to sediment.

5. Filter through two layers of cotton (or similar) using a funnel and transfer to centrifuge tubes.

6. Transfer $\sim 190 \mathrm{ml}$ filtrate to each of four $250 \mathrm{ml}$ centrifuge tubes. Balance tubes, and centrifuge at 3,000 $\times \mathrm{g}$ for $5 \mathrm{~min}$ in a $6 \times 250 \mathrm{ml}$ precooled angle rotor.

7. Pour supernatants carefully into fresh centrifuge tubes (avoid transferring the pellets), balance and centrifuge at $18,000 \times g$ for $10 \mathrm{~min}$.

8. Discard the supernatants gently without disturbing the pellets and resuspend each pellet in $1 \mathrm{ml}$ of 1x mannitol gradient buffer using a paint brush. Total volume of resuspended pellets 8-10 $\mathrm{ml}$.

9. Prepare two Percoll step gradients using plastic Pasteur pipettes. Avoid mixing the bands by gently layering first the $50 \%$, then the $28 \%$ and finally the $20 \%$ Percoll (all in mannitol) on top of each other in $50 \mathrm{ml}$ centrifuge tubes.

10. Gently layer the crude fraction (4-5 $\mathrm{ml}$ maximum per gradient) on top of the two Percoll step gradients.

11. Balance tubes and centrifuge at $40,000 \times g$ for 30 min using an $8 \times 50 \mathrm{ml}$ pre-cooled angle rotor (see Figure $1 \mathrm{~A}$ ).

12. Transfer the mitochondrial band from each tube using a Pasteur pipette to new $50 \mathrm{ml}$ tubes, fill up to $40 \mathrm{ml}$ with wash buffer and mix.

13. Balance the two tubes against each other and centrifuge at $18,000 \times g$ for $10 \mathrm{~min}$.

14. Carefully remove supernatant, resuspend the very loose pellets with wash buffer, fill up to $40 \mathrm{ml}$ with wash buffer and mix.

15. Balance and centrifuge at $18,000 \times g$ for $10 \mathrm{~min}$ (see Figure 1B).

16. Remove supernatant and resuspend the very loose pellets using a paint brush in $1 \mathrm{ml} 1 \mathrm{x}$ mannitol buffer and gently layer on top of two $28 \%$ Percoll sucrose gradients.

17. Balance and centrifuge at $40,000 \times g$ for 30 min using the $8 \times 50 \mathrm{ml}$ rotor (see Figure $1 \mathrm{C}$ ).

18. Transfer the mitochondrial bands to two fresh $50 \mathrm{ml}$ centrifuge tubes, fill up to $40 \mathrm{ml}$ with wash buffer and mix.

19. Centrifuge at $18,000 \times g$ for $10 \mathrm{~min}$. 
20. Carefully remove supernatant and repeat wash (as steps 13-14) of pellets (see Figure 1D).

21. Remove supernatant and resuspend each pellet in $500 \mu \mathrm{l}$ wash buffer. Add $5 \%(\mathrm{v} / \mathrm{v})$ DMSO for freezing of the intact organelles. The final volume from each pellet is around $800 \mu \mathrm{l}$ containing 4-6 mg (total 8-12 mg) mitochondrial protein.

22. Snap freeze and store aliquots of $100-200 \mu \mathrm{l}$ in liquid nitrogen. In this way, the mitochondria maintain their intactness and respiratory function (see below) for months, if quickly thawed shortly before use.

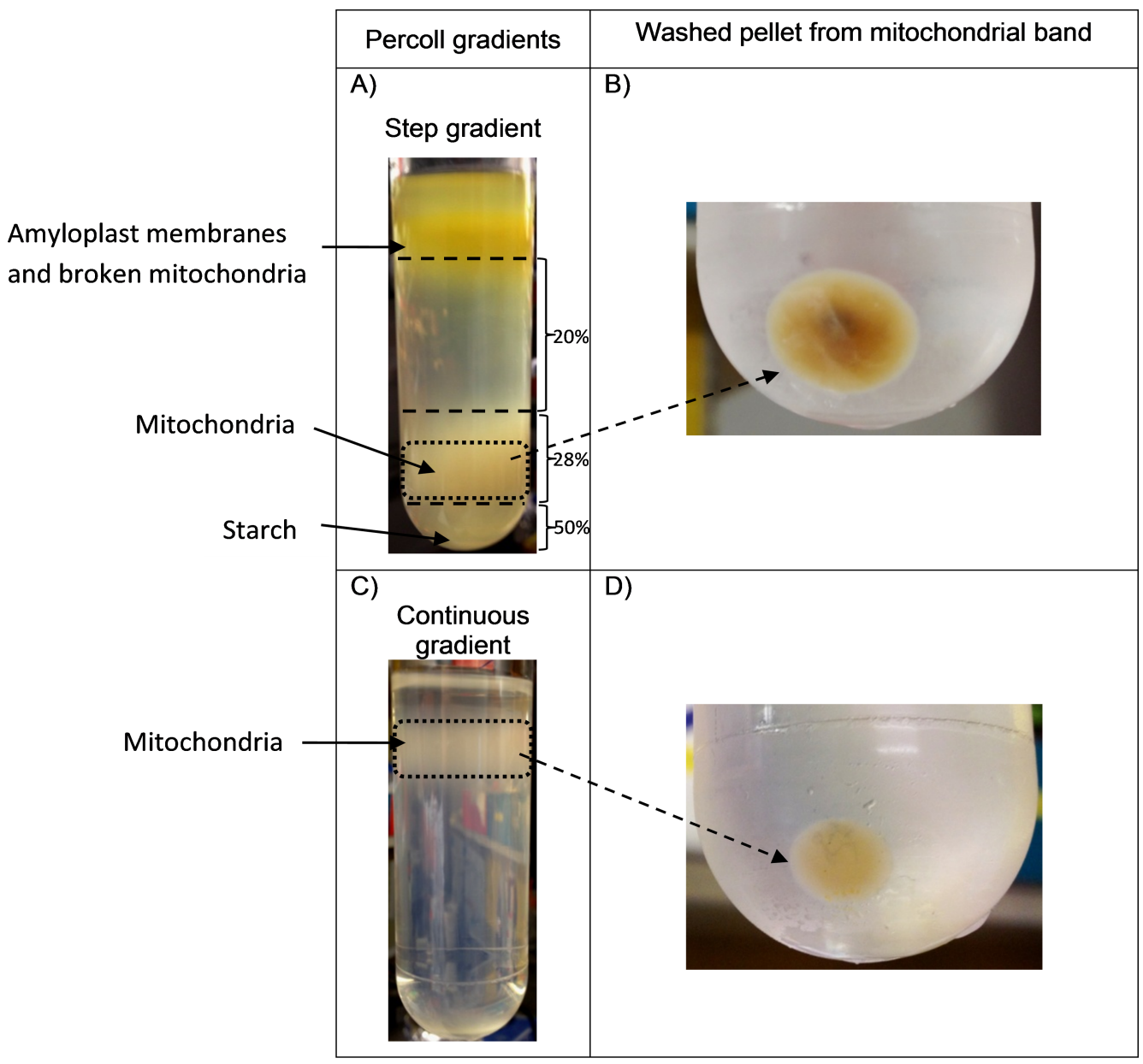

Figure 1. Percoll gradient purification of potato tuber mitochondria. A). Step gradient with a yellowish mitochondrial band at the $28 \%$ - 50\% Percoll interface and a starch pellet (after step 11). B). The pellet obtained after removing the mitochondrial band from the step gradient and washing it (after step 15). The dark center consists of peroxisomes (Struglics et al., 1993). C). Continuous gradient with a whitish mitochondrial band (after step 17). D). The final pellet obtained after removing the mitochondrial band from the continuous gradient and washing it (after step 20). 


\section{Representative data}

Properties of the isolated mitochondria

1. The mitochondria isolated from potato tubers using this protocol have highly intact outer membranes as judged by $>97 \%$ latency of cytochrome c oxidase and are highly purified as judged by the high specific activity of cytochrome c oxidase $\left(3.5 \mu \mathrm{mol} \mathrm{mg} \mathrm{min}^{-1}\right)$. The respiration rates in state 3 (presence of ADP) using single substrates (NADH, succinate and malate) are $150-350 \mathrm{nmol} \mathrm{O}_{2} \mathrm{mg}^{-1} \mathrm{~min}^{-1}$, the respiratory control ratio of 2.5-3.5 and the ADP/O ratio 1.7-2.0 all depending on the substrate, the preparation and the cultivar. This is fully consistent with previous studies (Neuburger et al., 1982; Rasmusson and Møller, 1990; Struglics et al., 1993).

2. The mitochondria were judged to be $>95 \%$ pure by western blotting (Salvato et al., 2014), which is consistent with measurements of marker enzymes and marker compounds in previous studies (Neuburger et al., 1982; Struglics et al., 1993).

3. Using one-dimensional polyacrylamide gel electrophoresis to separate the mitochondrial proteins according to size followed by tryptic digestion, separation of the tryptic peptides by liquid chromatography and identification by mass spectrometry a total of 1,060 different proteins were identified including about 500 proteins not previously identified in plant mitochondria (Salvato et al., 2014).

4. Similar methods can be used to isolate mitochondria from other tissues and species. However, the homogenization methods will probably have to be changed as does the Percoll concentration used to collect the mitochondria and purify them further ( $28 \%$ here). See Meyer and Millar (2008) for a method for isolating mitochondria from Arabidopsis cell cultures. Isolating mitochondria from green leaves is more difficult because of the large amount of chloroplasts and thylakoid membranes released from the tissue, and Arabidopsis leaves are particularly difficult (Keech et al., 2005).

\section{$\underline{\text { Recipes }}$}

1. Extraction medium [600 (300) $\mathrm{ml}, \mathrm{pH} 7.3]$

\begin{tabular}{|l|l|l|}
\hline Chemical & Concentration & g/L \\
\hline Mannitol & $0.9 \mathrm{M}$ & 163.95 \\
\hline MOPS & $30 \mathrm{mM}$ & 6.28 \\
\hline EDTA & $3 \mathrm{mM}$ & 0.87 \\
\hline L-Cysteine & $25 \mathrm{mM}$ & 3.03 \\
\hline BSA & $0.3 \%(w / v)$ & 3.00 \\
\hline
\end{tabular}


Dissolve mannitol, MOPS and EDTA in double-distilled water $\left(\mathrm{ddH}_{2} \mathrm{O}\right)$

Adjust $\mathrm{pH}$ to 7.2 and transfer $300 \mathrm{ml}$ to new container to use as wash buffer

On day of use add cysteine and BSA to the remaining $300 \mathrm{ml}$, adjust to $\mathrm{pH} 7.3$ with $\mathrm{KOH}$.

2. Wash buffer (900 ml, pH 7.2)

\begin{tabular}{|l|l|l|}
\hline Chemical & Concentration & g/L \\
\hline Mannitol & $0.3 \mathrm{M}$ & 54.65 \\
\hline MOPS & $10 \mathrm{mM}$ & 2.07 \\
\hline EDTA & $1 \mathrm{mM}$ & 0.29 \\
\hline
\end{tabular}

Use extraction medium (no cysteine and BSA) and dilute 3-fold by adding $\mathrm{dd}_{2} \mathrm{O}$ Include $0.1 \%$ BSA if the mitochondria are to be used in a non-proteomics context

3. Gradient buffers

a. $2 x$ mannitol buffer (150 ml, $\mathrm{pH} 7.2)$

\begin{tabular}{|l|l|l|}
\hline Chemical & Concentration & g/L \\
\hline Mannitol & $0.6 \mathrm{M}$ & 109.3 \\
\hline MOPS & $20 \mathrm{mM}$ & 4.14 \\
\hline BSA & $0.2 \%(\mathrm{w} / \mathrm{v})$ & 2.0 \\
\hline
\end{tabular}

Use $35 \mathrm{ml}$ for each of the two step gradients and dilute the remaining $115 \mathrm{ml}$ 2-fold to use for resuspending pellets.

b. $2 x$ sucrose buffer $(100 \mathrm{ml}, \mathrm{pH} 7.2)$

\begin{tabular}{|l|l|l|}
\hline Chemical & Concentration & g/L \\
\hline Sucrose & $0.6 \mathrm{M}$ & 205.4 \\
\hline MOPS & $20 \mathrm{mM}$ & 4.14 \\
\hline BSA & $0.2 \%(\mathrm{w} / \mathrm{v})$ & 2.0 \\
\hline
\end{tabular}

4. Percoll gradients

Total volume $35 \mathrm{ml}$ without samples

a. Step gradient

\begin{tabular}{|c|c|c|c|}
\hline $\begin{array}{c}\text { Percoll, } \\
\%(\mathrm{v} / \mathrm{v})\end{array}$ & $\begin{array}{c}\mathrm{ddH}_{2} \mathrm{O}, \\
\%\end{array}$ & $\begin{array}{c}2 \times \text { mannitol } \\
\text { buffer, } \%\end{array}$ & $\begin{array}{c}\text { Volume per } \\
\text { gradient, } \mathrm{ml}\end{array}$ \\
\hline 20 & 30 & 50 & 17.5 \\
\hline 28 & 22 & 50 & 11.67 \\
\hline 50 & - & 50 & 5.83 \\
\hline
\end{tabular}


b. Continuous gradient

\begin{tabular}{|c|c|c|c|}
\hline $\begin{array}{c}\text { Percoll, } \\
\%(v / v)\end{array}$ & $\begin{array}{c}\mathrm{dd} \mathrm{H}_{2} \mathrm{O}, \\
\%\end{array}$ & $\begin{array}{c}\text { 2x sucrose } \\
\text { buffer, } \%\end{array}$ & $\begin{array}{c}\text { Volume per } \\
\text { gradient, } \mathrm{ml}\end{array}$ \\
\hline 28 & 22 & 50 & 35 \\
\hline
\end{tabular}

Very carefully add the three layers of the step gradient one by one (highest first) holding the $50 \mathrm{ml}$ tube at a 45 degree angle to avoid mixing

\section{Acknowledgements}

This work was supported by the Danish Council for Independent Research - Natural Sciences (to I.M.M.) and the OECD Cooperative Research Programme: Biological Resource Management for Sustainable Agricultural Systems (2012 sabbatical fellowship to J.J.T.).

The method was published in Neuburger et al. (1982) and it is an adaptation of the methods used by Neuburger et al. (1982), Struglics et al. (1993) and Considine et al. (2002).

\section{References}

1. Considine, M. J., Goodman, M., Echtay, K. S., Laloi, M., Whelan, J., Brand, M. D. and Sweetlove, L. J. (2003). Superoxide stimulates a proton leak in potato mitochondria that is related to the activity of uncoupling protein. $J$ Biol Chem 278(25): 22298-22302.

2. Keech, O., Dizengremel, P. and Gardeström, P. (2005). Preparation of leaf mitochondria from Arabidopsis thaliana. Physiologia Plantarum 124(4): 403-409.

3. Meyer, E. H. and Millar, A. H. (2008). Isolation of mitochondria from plant cell culture. In: Posch (ed). Methods Mol Biol. Humana Press. vol. 425: 2D PAGE: Sample Preparation and Fractionation, Volume $2 \mathrm{~A}$.

4. Neuburger, M., Journet, E. P., Bligny, R., Carde, J. P. and Douce, R. (1982). Purification of plant mitochondria by isopycnic centrifugation in density gradients of Percoll. Arch Biochem Biophys 217(1): 312-323.

5. Rasmusson, A. G. and Møller, I. M. (1990). NADP-utilizing enzymes in the matrix of plant mitochondria. Plant Physiol 94(3): 1012-1018.

6. Salvato, F., Havelund, J. F., Chen, M., Rao, R. S., Rogowska-Wrzesinska, A., Jensen, O. N., Gang, D. R., Thelen, J. J. and Møller, I. M. (2014). The potato tuber mitochondrial proteome. Plant Physiol 164(2): 637-653.

7. Struglics, A., Fredlund, K. M., Rasmusson, A. G. and Møller, I. M. (1993). The presence of a short redox chain in the membrane of intact potato tuber peroxisomes and the 
association of malate dehydrogenase with the peroxisomal membrane. Physiologia Plantarum 88(1): 19-28. 